\title{
ANNOUNCEMENT
}

\section{Announcement Regarding Author Order in Paper 266-2011-9714}

(c) Springer Science+Business Media, LLC and International Society of Aesthetic Plastic Surgery 2012

The article entitled "Subpectoral and Precapsular Implant Repositioning Technique: Correction of the Capsular Contracture and Implant Malposition" (DOI 10.1007/ s00266-011-9714-z) was published in Volume 35, Number 6, December 2011, pp. 1126-1132. Soon after publication, Dr. Ung Sik Jin contacted the Editorial Office requesting a change in the order of author names, from Hong Ki Lee, Ung Sik Jin, and Yoon Ho Lee to Ung Sik Jin, Hong Ki
Lee, and Yoon Ho Lee. At the time, Dr. Ung Sik Jin's coauthors declined to permit a change of order. Early in 2012, the Editorial Office was contacted again, this time with all the authors giving permission for the new order of authors' names. Considering the circumstances, Springer has chosen not to print an erratum regarding the change. We do, however, invite the readership to decide for themselves the appropriate author order for this article. 